\title{
PREFERENSI MASYARAKAT TERHADAP MAKANAN BERBAHAN BAKU SAGU (Metroxylon $s a g u$ Rottb) SEBAGAI ALTERNATIF SUMBER KARBOHIDRAT DI KABUPATEN LUWU DAN LUWU UTARA SULAWESI SELATAN (Community Preferences Towards Sago-Based Food (Metoxylon sagu Rottb) as an Alternative of Carbobydrate Sources in Lurwu and North Luwn Regencies South Sulawesi Province)
}

\author{
Nur Hayati $i^{1}$, Rini Purwanti ${ }^{2} \&$ Abd. Kadir $W^{3}$ \\ ${ }^{1,2,3}$ Balai Penelitian Kehutanan Makassar \\ Jl. Perintis Kemerdekaan Km. 16,5 PO Box 1560 Makassar \\ e-mail: bpk_makassar@dephut.go.id
}

Diterima 18 September 2013, direvisi 6 Februari 2014, disetujui 20 Februari 2014

\begin{abstract}
Sago is one of carbohydrate sources and raw material of traditional foods in South Sulawesi Province, such as kapurung, dange, bagea, sinole and cendol. Sago should be promoted as one of alternative food sources, as it will reduce national food security problems. The purpose of this study is to determine factors affecting community decision to use sago as an alternative of carbohydrate sources. Method used for this study was survey in which purposive random sampling was carried out and sago consumers were the study target. Logistic regression analysis was used to analyze the data. The results showed that in Luwn and North Luwn Regencies, there were several reasons why community used sago as an alternative of carbohydrate source, i.e.: good taste, raw material was easy to obtain, community often ate sago instead rice for their staple foods, and the price was less expensive compared to rice. Futher more, the analyses results found that consumers' decision to consume sago was influenced by ethnicity, education, type of processed food and rice price.
\end{abstract}

Keywords: Community preferences, sago, carbobydrate alternative, foodsources

\begin{abstract}
ABSTRAK
Sagu merupakan salah satu sumber karbohidrat dan bahan dasar dalam pembuatan makanan tradisional di Sulawesi Selatan misalnya kapurung, dange, bagea, sinole, cendol dan lain-lain. Apabila sagu dikembangkan akan menjadi salah satu sumber pangan alternatif yang dapat meringankan masalah ketahanan pangan nasional. Tujuan penelitian ini adalah untuk mengetahui faktor-faktor yang mempengaruhi keputusan masyarakat untuk menggunakan sagu sebagai alternatif sumber karbohidrat. Pengambilan sampel menggunakan metode purposif secara random sampling terhadap konsumen sagu yang ditemui pada saat penelitian. Untuk mengetahui faktor-faktor yang mempengaruhi keputusan masyarakat dalam menggunakan sagu sebagai alternatif sumber karbohidrat di Sulawesi Selatan digunakan Analisis Regresi Logistik. Hasil penelitian menunjukkan bahwa di Kabupaten Luwu dan Luwu Utara terdapat beberapa alasan masyarakat menyukai sagu, yaitu rasanya yang enak, bahannya mudah didapat, faktor kebiasaan, sebagai pengganti beras, dan harganya yang lebih murah jika dibanding dengan beras. Lebih jauh, hasil analisis regresi logistik menunjukkan bahwa keputusan konsumen dalam mengkonsumsi makanan berbahan baku sagu dipengaruhi oleh suku, pendidikan, jenis makanan olahan, dan harga beras.
\end{abstract}

Kata kunci: Preferensi masyarakat, sagu, alternatif karbohidrat, sumber pangan

\section{PENDAHULUAN}

Tanaman sagu (Metroxylon sp) merupakan salah satu tanaman penghasil karbohidrat yang penting kedudukannya sebagai bahan makanan sesudah padi, jagung, dan umbi-umbian. Sagu memiliki kandungan karbohidrat (kalori) yang memadai dan memiliki kemampuan substitusi pati sagu dalam industri pangan. Sagu juga sangat berpotensial untuk diolah menjadi bioetanol. Dengan demikian pengelolaan sagu di Indonesia memiliki prospek yang sangat menjanjikan untuk ketahanan pangan dan energi nasional di masa mendatang. 
Potensi luas hutan sagu di Indonesia adalah kurang lebih 1.250.000 ha dan budidaya sagu kurang lebih 148.000 ha. Potensi tesebut sampai saat ini belum dimanfaatkan secara maksimal. Sagu dapat tumbuh di daerah rawa atau tanah marginal (terbengkalai) di mana tanaman penghasil karbohidrat lainnya sukar untuk tumbuh dengan wajar (Budiono, 2009).

Potensi sagu di Indonesia dari sisi luas areal sangat besar. Sekitar 60\% areal sagu dunia berasal dari di Indonesia. Data yang ada menunjukkan bahwa areal sagu Indonesia menurut Prof. Flach mencapai 1,2 juta ha dengan produksi berkisar 8,413,6 juta ton per tahun, dan sekitar $90 \%$ berada di Papua. Sagu merupakan salah satu makanan pokok beberapa daerah di Indonesia Bagian Timur, bukan hanya di Provinsi Sulawesi Selatan (daerah Luwu), tapi juga di Papua, Maluku, Sulawesi Utara, dan sejumlah daerah di Nusa Tenggara. Konsumsi sagu sebagai makanan pokok, antara lain dalam bentuk makanan tradisional seperti papeda, kapurung, dange, bagea, sinole, cendol dan sagu bakar (Pusat Penelitian dan Pengembangan Perkebunan, 2013).

Produksi sagu di Sulawesi Selatan pada tahun 2010 sebesar 1.065 ton. Total potensi lahan yang dikembangkan untuk sagu di Sulawesi Selatan seluas 4.102 ha, yang berada di Kabupaten Luwu seluas 1.462 ha $(35,6 \%)$ dan di Luwu Utara seluas 1.590 ha $(38,8 \%)$, sehingga kedua kabupaten tersebut merupakan daerah penghasil sagu terbesar di Sulawesi Selatan. Namun, saat ini sebagian perkebunan sagu di lokasi penelitian sudah beralih fungsi menjadi persawahan, perkebunan bahkan menjadi areal pembangunan perumahan (Badan Koordinasi Penanaman Modal, 2010).

Tanaman sagu sangat potensial untuk dikembangkan sebagai bahan pangan alternatif bagi masyarakat Indonesia selain padi. Hal ini dijelaskan oleh Menteri Pertanian Suswono dalam kegiatan lokakarya nasional sagu yang berlangsung tanggal 14 Oktober 2010 di Bogor (Bisnis Indonesia, 2010). Lebih lanjut Suswono menjelaskan bahwa sagu menghasilkan pati kering sebagai bahan pangan sumber karbohidrat. Meskipun memiliki potensi sebagai pangan sumber karbohidrat alternatif non beras, namun hingga tahun 2009 angka konsumsi sagu masyarakat Indonesia masih rendah, yakni $0,41 \mathrm{~kg} /$ kapita/ tahun. Pemanfaatan sagu sebagai pangan sumber karbohidrat ternyata secara nasional juga paling rendah dibandingkan komoditas pangan non beras lainnya seperti singkong, ubi jalar, kentang, dan jagung. Kadar karbohidrat sagu setara dengan karbohidrat yang terdapat pada tepung beras, singkong dan kentang, bahkan kadar karbohidrat tepung sagu relatif lebih tinggi jika dibandingkan dengan tepung jagung dan terigu. Kandungan energi dalam tepung sagu, hampir setara dengan bahan pangan pokok lain berbentuk tepung seperti beras, jagung, singkong, kentang dan terigu. Tulisan ini diharapkan dapat memberikan gambaran faktor-faktor apa saja yang mempengaruhi keputusan masyarakat untuk menggunakan sagu sebagai alternatif sumber karbohidrat di Sulawesi Selatan.

\section{METODE PENELITIAN}

\section{A. Waktu dan Lokasi Penelitian}

Penelitian ini dilaksanakan pada bulan Juni sampai Oktober 2009. Lokasi penelitian di Kabupaten Luwu dan Kabupaten Luwu Utara Provinsi Sulawesi Selatan. Lokasi penelitian tersebut ditentukan secara sengaja (purposive), yaitu Sulawesi Selatan sebagai salah satu sentra produksi sagu.

\section{B. Sumber dan Pengumpulan Data}

Sumber data yang digunakan dalam penelitian ini adalah data primer. Data primer diperoleh di lapangan dari konsumen sagu melalui wawancara dengan menggunakan kuisioner terstruktur.

Pengambilan sampel responden menggunakan metode purposive secara random sampling terhadap konsumen sagu yang ditemui pada saat penelitian. Jumlah responden yang diwawancarai sebanyak 120 orang yang berasal dari Kabupaten Luwu yaitu Desa Suli, Desa Tirowali, Desa Padang Sappa dan Desa Lamasi dan Kabupaten Luwu Utara yaitu Desa Meli, Desa Sassa', Desa Waeulawi dan Desa Pengkajoang.

\section{Analisis Data}

Untuk mengetahui faktor-faktor yang mempengaruhi keputusan masyarakat dalam menggunakan sagu sebagai alternatif sumber karbohidrat di Sulawesi Selatan digunakan Analisis Regresi Logistik. Analisis ini merupakan model regresi untuk menganalisis data dengan variabel 
dikotomus (bernilai 1 dan 0), $\mathrm{Y}=1$ menyatakan keputusan mengkonsumsi makanan berbahan baku sagu dan $\mathrm{Y}=0$ menyatakan keputusan tidak mengkonsumsi makanan berbahan baku sagu. Regresi logistik memiliki distribusi data yang tidak normal (Kuncoro, 2007).

Analisis model regresi logistik pada penelitian ini menggunakan bantuan program SPSS 15 for windows. Analisis ini untuk mengetahui penentu konsumen mengkonsumsi makanan berbahan baku sagu di Kabupaten Luwu dan Kabupaten Luwu Utara berdasarkan variabel-variabel independen yang ditentukan.

Bentuk umum model regresi logistik (Gujarati, 2003);

$P_{i}=E\left(Y=1 \mid X_{i}\right)=\frac{1}{1+e^{-\left(\beta_{0}+\beta_{1} x_{i}\right)}}$

Persamaan (1) dapat disederhanakan menjadi

$P_{i}=\frac{1}{\left(1+e^{-Z_{i}}\right)}=\frac{e^{0}}{\left(e^{0}+e^{-Z_{i}}\right)}=\frac{e^{Z_{i}-Z_{i}}}{\left(e^{Z_{i}-Z_{i}}+e^{-Z_{i}}\right)}=\frac{e^{Z_{i}-Z_{i}}}{\left(e^{Z_{i}} e^{-Z_{i}}+e^{-Z_{i}}\right)}$

$P_{i}=\frac{e^{Z_{i}-Z_{i}}}{\left(e^{Z_{i}} e^{-Z_{i}}+e^{-Z_{i}}\right)}=\frac{e^{Z_{i}}}{\left(e^{Z_{i}}+1\right)} \frac{e^{-Z_{i}}}{e^{-Z_{i}}}=\frac{e^{Z_{i}}}{\left(e^{Z_{i}}+1\right)}$

$P_{i}=\frac{e^{Z_{i}}}{\left(e^{Z_{i}}+1\right)}$

Keterangan:

$\mathrm{Zi}=\beta 0+\beta 1 \mathrm{xi}$

E adalah euler number (2,718).

Pi adalah probabilitas suatu kejadian, $(0<\mathrm{Pi}<1)$

dimana $-\infty<\mathrm{Z}<+\infty$

Tranformasi model regresi logistik adalah

$L_{i}=\ln \left(\frac{p_{i}}{1-p_{i}}\right)=\beta_{0}+\beta_{1} X_{1}+\beta_{2} X_{2}+\ldots \ldots .+\beta_{n} X_{n}$

Berdasarkan model logistik pada persamaan (3), dalam penelitian ini dikembangkan model sebagai berikut:

$L_{i}=\ln \left(\frac{p_{i}}{1-p_{i}}\right)=\beta_{0}+\beta_{1} S K+\beta_{2} P d d k+\beta_{3} J O+\beta_{4} P d p t+\beta_{5} U M+\beta_{6} H B+\varepsilon$
Keterangan:

$\mathrm{P}$ adalah probabilitas seorang konsumen memilih nilai variabel dependen (1: mengkonsumsi makanan berbahan baku sagu dan 0: tidak mengkonsumsi sagu)

SK adalah suku responden (dummy; 0: suku lainnya, 1: Suku Luwu)

Pddk adalah tingkat pendidikan responden (dummy; 0: SD atau tidak sekolah, 1: SMP atau tingkat pendidikan lebih tinggi).

JO adalah jenis makanan olahan (dummy; 1: kapurung, 0: lainnya)

Pdpt adalah pendapatan responden.

UM adalah umur responden.

HB adalah harga beras.

$\varepsilon$ adalah errorterm

Berdasarkan model tersebut dapat diketahui bagaimana keputusan seorang konsumen untuk mengkonsumsi makanan berbahan baku sagu. Keputusan tersebut akan terlihat berdasarkan pengaruh variabel-variabel bebas (independent) terhadap variabel tidak bebas (dependent).

\section{HAS IL DAN PEMBAHASAN PENELITIAN}

\section{A. Kondisi Sosial Ekonomi Responden}

Untuk mengetahui preferensi masyarakat di Kabupaten Luwu dan Luwu Utara terhadap makanan berbahan sagu, terdapat beberapa karakteristik dari responden yang dicatat, antara lain: umur, pendidikan, suku, jumlah tanggungan keluarga, dan besarnya pendapatan responden.

\section{Umur Responden}

Komposisi umur responden berkisar antara 17 - 73 tahun yang dapat dilihat pada Tabel 1.

Tabel 1. Komposisi umur responden

Table 1. Age composition of respondents

\begin{tabular}{ccc}
\hline Kelas umur (tahun) & \multicolumn{2}{c}{$\begin{array}{c}\text { Prosentase jumlah orang } \\
\text { Percentage number of people }(\%)\end{array}$} \\
\cline { 2 - 3 } Range of age (year) & Luwu & Luwu Utara \\
\hline $15-34$ & 23,3 & 30,0 \\
$35-54$ & 48,3 & 55,0 \\
$>54$ & 28,3 & 15,0 \\
\hline Jumlah (total) & 100 & 100 \\
\hline
\end{tabular}

Sumber (Source): Data primer, 2009 (Primary data, 2009) 
Berdasarkan Tabel 1 diketahui bahwa responden di lokasi penelitian kebanyakan berada pada usia produktif. Dengan banyaknya responden yang berada dalam kelompok usia produktif di lokasi penelitian memungkinkan daerah tersebut berkembang. Hal ini disebabkan pada usia produktif biasanya seseorang cepat dalam mengambil keputusan dalam alih teknologi dan diversifikasi sumber pangan.

\section{Pendidikan Responden}

Pendidikan merupakan salah satu indikator untuk keberhasilan penerapan teknologi pemanenan dan pascapanen pada suatu daerah khususnya yang berhubungan dengan kegiatan pengelolaan sagu. Tingkat pendidikan akan mempengaruhi cara berpikir seseorang terutama dalam menganalisis suatu masalah. Tingkat pendidikan responden dapat dilihat pada Tabel 2 .

Tabel 2. Komposisi tingkat pendidikan responden Table 2. Composition of educationlevel of respondents

\begin{tabular}{lcc}
\hline \multicolumn{1}{c}{\begin{tabular}{c} 
Tingkat pendidikan \\
\multicolumn{1}{c}{ (Education leve) }
\end{tabular}} & \multicolumn{2}{c}{$\begin{array}{c}\text { Prosentase jumlah orang } \\
\text { Percentage number of people (\%) }\end{array}$} \\
\cline { 2 - 3 } & Luwu & Luwu Utara \\
\hline Rendah ( $\leq$ SD) & 35,0 & 30,0 \\
Menengah (SMP-SMA) & 23,3 & 28,3 \\
Tinggi (Perguruan Tinggi) & 41,7 & 41,7 \\
\hline Jumlah(total) & 100 & 100 \\
\hline
\end{tabular}

Sumber (Source): Data primer, 2009 (Primary data, 2009)

Tabel 3. Komposisi responden berdasarkan suku

Table 3. Composition of respondents by etnic group

\begin{tabular}{|c|c|c|}
\hline \multirow[t]{2}{*}{$\begin{array}{c}\text { Suku } \\
\text { (Etnic group) }\end{array}$} & \multicolumn{2}{|c|}{$\begin{array}{c}\text { Prosentase jumlah orang } \\
\text { Percentage number of people } \\
(\%)\end{array}$} \\
\hline & Luwu & Luwu Utara \\
\hline Luwu & 78,3 & 60,0 \\
\hline Bugis & 20,0 & 36,7 \\
\hline Ambon & 1,7 & 0 \\
\hline Jawa & - & 1,7 \\
\hline Makassar & - & 1,6 \\
\hline Jumlah (total) & 100 & 100 \\
\hline
\end{tabular}

Sumber (Source): Data primer, 2009 (Primary data, 2009)

\section{Jumlah Tanggungan Keluarga}

Jumlah tanggungan keluarga responden di lokasi penelitian dapat dilihat pada Tabel 4.

Tabel 4 menunjukkan bahwa konsumen sagu mayoritas mempunyai tanggungan sebanyak 3-5 orang. Jumlah anggota yang banyak seringkali
Dari Tabel 2 diketahui bahwa tingkat pendidikan konsumen di Kabupaten Luwu dan Kabupaten Luwu Utara sebagian besar berpendidikan tinggi (41,7\%). Hal ini berarti prosentase jumlah responden yang berpendidikan tinggi lebih besar dibanding prosentase responden yang berpendidikan rendah atau menengah. Kenyataan tersebut menunjukkan kesadaran responden akan pentingnya pendidikan sudah cukup tinggi.

\section{Suku}

Komposisi responden berdasarkan sukunya dapat dilihat pada Tabel 3 .

Berdasarkan Tabel 3 diketahui bahwa konsumen sagu umumnya bersuku Luwu. Hal ini menunjukkan bahwa orang Suku Luwu gemar mengkonsumsi sagu sebagai sumber energi karbohidrat selain beras. 
Tabel 4. Jumlah tanggungan keluarga

Table 4. Number of family dependants

\begin{tabular}{|c|c|c|}
\hline \multirow{2}{*}{$\begin{array}{c}\text { Jumlah anggota keluarga (orang) } \\
\text { Number of family members } \\
\text { (person) }\end{array}$} & \multicolumn{2}{|c|}{$\begin{array}{c}\text { Prosentase jumlah orang } \\
\text { Percentage number of people }(\%)\end{array}$} \\
\hline & Luwu & Luwu Utara \\
\hline 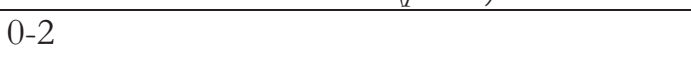 & 16,6 & 11,7 \\
\hline $3-5$ & 51,7 & 58,3 \\
\hline$\geq 6$ & 31,7 & 30,0 \\
\hline Jumlah (total) & 100 & 100 \\
\hline
\end{tabular}

Sumber (Source): Data primer, 2009 (Primary data, 2009)

\section{Pendapatan Responden}

Pendapatan yang dimaksud pada tulisan ini adalah seluruh nilai yang diperoleh responden dari hasil usahanya, baik yang berasal dari usaha sagu maupun yang berasal dari usaha yang lainnya, misalnya hasil pertanian, perkebunan, gaji pegawai, dan sebagainya. Pendapatan responden mayoritas berasal dari hasil pertanian dan perkebunan. Tingkat pendapatan konsumen sagu per bulan dapat dilihat pada Tabel 5.

Berdasarkan Tabel 5 dapat diketahui bahwa rata-rata tingkat pendapatan konsumen cukup bervariasi tergantung dari jenis pekerjaannya.

Tabel 5. Tingkat pendapatan responden per bulan

Table 5. Income level of respondents per month

\begin{tabular}{|c|c|c|}
\hline \multirow[t]{2}{*}{$\begin{array}{c}\text { Tingkat pendapatan (Rp). } \\
\text { (Level of income) }\end{array}$} & \multicolumn{2}{|c|}{$\begin{array}{c}\text { Prosentase jumlah orang } \\
\text { (Percentage number of people) } \\
(\%)\end{array}$} \\
\hline & Luwu & Luwu Utara \\
\hline $100.000-500.0000$ & 20,0 & 36,6 \\
\hline $600.000-1.000 .000$ & 36,7 & 31,7 \\
\hline$>1.000 .000$ & 43,3 & 31,7 \\
\hline Jumlah (total) & 100 & 100 \\
\hline
\end{tabular}

Sumber (Source): Data primer, 2009 (Primary data, 2009)

\section{B. Preferensi Konsumen dalam Meng- konsumsi Sagu}

Preferensi atau selera merupakan sebuah konsep yang digunakan pada ilmu sosial, khususnya ekonomi. Preferensi ini mengasumsikan pilihan realitas atau imajiner antara alternatif-alternatif dan kemungkinan dari pemeringkatan alternatif tersebut, berdasarkan kesenangan, kepuasan, gratifikasi, pemenuhan, kegunaan yang ada. Lebih luas lagi, bisa dilihat sebagai sumber dari motivasi. Dalam ilmu kognitif, preferensi individu memungkinkan pemilihan tujuan (goal).

Preferensi didefinisikan sebagai tindakan untuk memilih yang ditentukan oleh banyak faktor. Menurut Abello dan Bernaldez (1986) dalam Permata (2000) faktor-faktor yang mempengaruhi preferensi masyarakat, antara lain adalah usia, jenis kelamin, tingkat pendidikan, tingkat sosial, dan budaya. Preferensi juga ditentukan oleh rasa keterkaitan seseorang terhadap suatu tempat dimana orang tersebut bisa hidup atau tinggal lama di dalamnya. Dengan kata lain, preferensi seseorang juga dipengaruhi oleh rasa familiaritas (Nassar, 1988).

Menurut 120 responden yang dilibatkan dalam penelitian, $74,17 \%$ responden menyatakan suka makan sagu dengan alasan rasanya khas (32,5\%) sedangkan $35,5 \%$ tidak suka makan sagu dengan alasan sulit mendapatkan sagu (dari persediaan dan lokasi) (62,5\%) dan tidak terbiasa makan sagu $(37,5 \%)$. Alasan suka, dan tidak suka ini menjadi dasar dalam keputusan mengkonsumsi sagu. Berdasarkan penelitian, 20,83\% responden mengkonsumsi sagu hanya karena faktor kebiasaan. Hal ini banyak dijumpai di daerah Luwu Utara yang hampir tiap hari masyarakatnya mengkonsumsi sagu. Kebiasaan makan sagu ini 
sudah ada sejak dari nenek moyang mereka. Apabila satu hari saja tidak makan sagu, mereka merasa "haus". Permintaan sagu akan meningkat apabila menjelang bulan Ramadhan, karena mereka menjadikan kapurung sebagai makanan pembuka puasa. Bahkan, setiapkali ada pesta atau upacara adat selalu ada menu makanan berbahan baku sagu.

Hasil penelitian menunjukkan bahwa ternyata jenis olahan sagu juga mempengaruhi preferensi konsumsi sagu. Jenis makanan olahan yang digemari di Kabupaten Luwu adalah kapurung $(98,33 \%)$ sedangkan di Luwu Utara kapurung $54,1 \%$ dan dange 45,9\%. Di Luwu Utara juga terjadi perbedaan pola konsumsi sagu, misalnya di daerah pesisir lebih menyukai jenis olahan "dange" karena dianggap lebih mengenyangkan dibanding "kapurung".

Masyarakat di Kabupaten Luwu Utara 52,46\% responden hampir tiap hari mengkonsumsi sagu, sedangkan di Kabupaten Luwu hanya 21,67\%. Hal ini mengindikasikan bahwa semakin jauh lokasi asal sagu, masyarakatnya cenderung jarang mengkonsumsi sagu, karena bahan baku sagu terbatas dan sulit mendapatkannya.

Hasil penelitian juga menunjukkan bahwa di Kabupaten Luwu Utara masyarakatnya (85,26\%) menjadikan sagu sebagai makanan pokok, tetapi ada kecenderungan angka ini semakin menurun apabila pihak pemerintah tidak menggalakkan program diversifikasi pangan. Hal ini juga terjadi karena semakin menyempitnya areal tanaman sagu. Lahanlahan sagu banyak yang dikonversi menjadi lahan perkebunan, jalan, perumahan dan perkantoran. Apabila dibiarkan terus tanpa adanya usaha rehabilitasi dan pembudidayaan sagu secara intensif maka pohon-pohon sagu akan semakin sulit dijumpai, sehingga sagu akan menjadi sumber karbohidrat yang mahal dan langka di pasaran. Hal ini tentunya akan semakin menambah ketergantungan masyarakat pada beras, sehingga ketahanan pangan pun terancam.

Oleh sebab itu, Pemerintah Kabupaten Luwu Utara telah menggagas penanaman sejuta pohon sagu. Ini dimaksudkan untuk membudidayakan pohon sagu yang mulai berkurang. Pemkab Luwu Utara mendatangkan tenaga ahli dari Institut Pertanian Bogor (IPB) yang ahli dibidang budidaya pohon sagu dan teknologi pengolahan sagu (Palopo Pos, 2011).

\section{Faktor-Faktor Yang Mempengaruhi Keputusan Masyarakat dalam Mengguna- kan Sagu}

Untuk melakukan pengujian terhadap signifikasi model, pada regresi logistik digunakan statistik uji G. Statistik uji $G$ bertujuan untuk menguji kesesuaian model dengan melihat pengaruh semua variabel bebas terhadap variabel tidak bebas di dalam model.Variabel bebas yang digunakan dalam penelitian ini sebanyak tujuh variabel. Berdasarkan hasil pengujian model secara simultan menggunakan statistik uji $G$, hasil output yang diperoleh nilai statistik uji $G$ sebesar 54,870 dan $p$-value $<\alpha=0,05$. Berdasarkan hasil tersebut $\mathrm{H}_{\text {。 }}$ ditolak yang berarti pada keputusan konsumen untuk mengkonsumsi makanan berbahan baku sagu di Kabupaten Luwu dan Kabupaten Luwu Utara minimal terdapat satu variabel bebas yang berpengaruh terhadap keputusan mengkonsumsi makanan berbahan baku sagu.

Tabel 6. Hasil analisis regresi logistik

Table 6. Resultof logistic regression analysis

\begin{tabular}{llrrrrrrr}
\hline \multirow{2}{*}{ Variabel } & & & & & & \multicolumn{2}{c}{ Odds } & \multicolumn{2}{c}{ 95.0\% C.I.for EXP(B) } \\
\cline { 8 - 9 } & B & S.E. & \multicolumn{1}{c}{ Wald } & Df & Sig. & rasio & Lower & \multicolumn{1}{c}{ Upper } \\
\hline Suku(1) & 1.792 & .755 & 5.636 & 1 & .018 & 6.000 & 1.367 & 26.342 \\
Pendidikan(1) & 1.724 & .787 & 4.800 & 1 & .028 & 5.609 & 1.199 & 26.235 \\
J_olahan(1) & -2.829 & .820 & 11.893 & 1 & .001 & .059 & .012 & .295 \\
Pendapatan & .000 & .000 & .002 & 1 & .965 & 1.000 & 1.000 & 1.000 \\
Umur & -.047 & .026 & 3.3981 & 1 & .065 & .954 & .908 & 1.003 \\
H_beras & -.020 & .005 & 19.139 & 1 & .000 & .980 & .971 & .989 \\
\hline
\end{tabular}

Sumber (Source): Analisis data primer, 2009 (Primary data analysed, 2009) 


\section{Uji model secara parsial}

Karena hasil uji simultan menolak hipotesis nol maka kemudian dapat dilakukan pengujian secara parsial menggunakan uji wald. Uji wald dilakukan untuk mengetahui ketepatan dari pengujian model. Berdasarkan hasil uji wald terlihat variabel bebas yang signifikan mempengaruhi keputusan untuk mengkonsumsi makanan berbahan baku sagu adalah variabel suku, pendidikan, jenis makanan olahan, dan harga beras, sedangkan variabel pendapatan dan umur tidak memiliki pengaruh yang signifikan.

Berdasarkan Tabel 6, peluang regresi logistik dengan transformasi logistik adalah:

$g(x)=106,95+1,79 \mathrm{SK}+1,72 \mathrm{Pddk}-2,83 \mathrm{JO}-0,02 \mathrm{HB}$

Selanjutnya dari nilai $\beta$ masing-masing variabel dalam model regresi logistik dapat dijelaskan sebagai berikut:

a. Suku (SK) berpengaruh secara signifikan terhadap keputusan konsumen mengkonsumsi makanan berbahan baku sagu. Ini menunjukkan bahwa suku tidak dapat dipisahkan dari mengkonsumsi sagu atau bahan makanan yang terbuat dari sagu. Pada lokasi penelitian, Suku Luwu yang merupakan suku asli di Kabupaten Luwu Utara dan Kabupaten Luwu sudah sejak dahulu mengkonsumsi sagu sebagai sumber karbohidrat. Sampai sekarang pun Suku Luwu masih gemar mengkonsumsi sagu, bahkan apabila tidak mengkonsumsi sagu dalam sehari ada sesuatu yang "kurang". Di lokasi penelitian terdapat beberapa suku yang menjadi obyek penelitian, antara lain Suku Bugis, Makassar, Ambon, dan Jawa.

b. Pendidikan (Pddk) secara signifikan berpengaruh positif terhadap keputusan konsumen mengkonsumsi makanan berbahan baku sagu. Ini menunjukkan bahwa semakin tinggi pendidikan maka peluang responden untuk memutuskan mengkonsumsi sagu semakin besar. Hal ini disebabkan karena semakin tinggi tingkat pendidikan seseorang, maka pengetahuan tentang kandungan gizi dan energi serta diversifikasi makanan juga semakin bertambah. Sebagai contoh bahwa kandungan kalori tepung sagu setiap 100 gram sebanyak 353 kalori, ternyata tidak kalah dibandingkan dengan kandungan kalori bahan pangan lainnya seperti jagung 361 kalori, beras giling 360 kalori, ubi kayu 195 kalori, dan ubi jalar 143 kalori (Ebookpangan, 2006). c. Jenis makanan olahan (JO) secara signifikan berpengaruh negatif terhadap keputusan konsumen mengkonsumsi makanan berbahan baku sagu. Ini menunjukkan bahwa jenis makanan olahan dari sagupenting dan menentukan apakah seseorang akan mengkonsumsinya. Kapurung merupakan salah satu jenis makanan olahan yang banyak disukai oleh responden.

d. Pendapatan (Pdpt) tidak berpengaruh secara signifikan terhadap keputusan konsumen mengkonsumsi makanan berbahan baku sagu. Ini menunjukkan bahwa harga makanan berbahan baku sagu cukup terjangkau oleh sebagian besar responden.

e. Umur (UM) tidak berpengaruh secara signifikan terhadap keputusan konsumen mengkonsumsi makanan berbahan baku sagu. Sagu merupakan makanan yang disukai oleh semua umur dan dapat dikatakan sebagai makanan tradisional.

f. Harga beras (HB) secara signifikan berpengaruh negatif terhadap keputusan konsumen mengkonsumsi makanan berbahan baku sagu. Ini menunjukkan bahwa semakin murah harga beras maka peluang responden untuk mengkonsumsi sagu semakin kecil. Hal ini disebabkan karena sagu sangat mudah didapatkan (banyak tumbuh di lahan-lahan masyarakat), harganya relatif murah (terjangkau) dan faktor kebiasaan masyarakat untuk mengkonsumsi sagu.

\section{Fungsi Peluang dan Odds Rasio}

Odds rasio merupakan ukuran untuk mengetahui tingkat risiko (kecenderungan), yaitu perbandingan antara peluang dua variabel bebas $\mathrm{Xj}$, antara kejadian-kejadian yang masuk kategori sukses dan yang gagal (Hosmer dan Lemeshow, 1989). Dalam penelitian ini odds rasio digunakan untuk mengetahui kecenderungan faktor-faktor yang berpengaruh terhadap keputusan mengkonsumsi makanan berbahan baku sagu.

Model persamaan regresi logistik yang terbentuk adalah:

$\hat{\pi}(x)=\frac{\exp (1,79 \text { Suku }+1,72 \text { Pendidikan }-2,83 \text { Jenis olahan }-0,02 h \arg a \text { beras })}{1+\exp (1,79 S u k u+1,72 \text { Pendidikan }}$ $1+\exp (1,79$ Suku $+1,72$ Pendidikan $-2,83$ Jenis olahan $-0,02 \mathrm{~h}$ arg a beras $)$

Menggunakan model peluang pada persamaan (5) dapat dihitung berapa peluang seorang konsumen untuk memutuskan mengkonsumsi 
makanan berbahan baku sagu. Sedangkan transformasi logit model persamaan di atas adalah sebagai berikut:

\section{$g(x)=1,79$ Suku $+1,72$ Pendidikan $-2,83$ Jenis olahan - 0,02 Harga beras}

Nilai odds rasio untuk suku adalah 6,00, yang berarti seseorang yang bersuku Luwu cenderung untuk mengkonsumsi makanan berbahan baku sagu sebesar 6 kali lebih sering dibandingkan suku lain (Bugis, Makassar, Ambon, dan Jawa). Odds rasio untuk pendidikan sebesar 5,609 menunjukkan bahwa semakin tinggi tingkat pendidikan yang ditamatkan seorang konsumen di lokasi penelitian, maka kecenderungan untuk mengkonsumsi makanan berbahan baku sagu sebesar 5 kali lebih sering bila berpendidikan SD atau tidak bersekolah. Nilai odds rasio untuk jenis makanan olahan sebesar 0,059 menunjukkan bahwa semakin gemar seorang konsumen makan jenis olahan "kapurung", maka kecenderungan untuk mengkonsumsi kapurung sebesar 0,059 kali bila mengkonsumsi makanan olahan lainnya selain kapurung. Odds rasio untuk harga beras sebesar 0,980 menunjukkan bahwa semakin murah harga beras maka kecenderungan untuk mengkonsumsi makanan berbahan baku sagu sebesar 0,980 kali bila harga beras mahal.

\section{Ketepatan Prediksi Model}

Ketepatan model fungsi peluang dapat dilihat berdasarkan klasifikasi objek penelitian. Tabel 7 menunjukkan keputusan untuk mengkonsumsi makanan berbahan baku sagu di Kabupaten Luwu dan Kabupaten Luwu Utara yang dengan tepat diklasifikasikan dan berapa yang salah diklasifikasikan. Dari 120 responden, terdapat 89 orang memutuskan untuk mengkonsumsi makanan berbahan baku sagu dan 31 orang tidak mengkonsumsi. Untuk yang mengkonsumsi ternyata prediksi yang dilakukan model 93,3\% tepat dan untuk yang tidak mengkonsumsi 54,8\%. Terjadi kesalahan prediksi 23 responden, 6 responden yang seharusnya memutuskan untuk mengkonsumsi sagu, tetapi tidak mengkonsumsi sagu dan 17 responden yang seharusnya tidak mengkonsumsi makanan berbahan baku sagu tetapi diprediksi mengkonsumsi sagu. Secara keseluruhan ketepatan prediksi model sebesar 83,3\%.

Tabel 7. Ketepatan prediksi model

Table 7. Model prediction accuracy

\begin{tabular}{|c|c|c|c|c|}
\hline \multirow{3}{*}{\multicolumn{2}{|c|}{$\begin{array}{l}\text { Observasi } \\
\text { (Observation) }\end{array}$}} & \multicolumn{3}{|c|}{ Prediksi (Prediction) } \\
\hline & & \multicolumn{2}{|c|}{$\begin{array}{l}\text { Keputusan mengkonsumsi } \\
\text { (Decision to consume) }\end{array}$} & \multirow{2}{*}{$\begin{array}{l}\text { Persentase } \\
\text { ketepatan } \\
\text { (Accuracy } \\
\text { percentage) } \\
\end{array}$} \\
\hline & & $\begin{array}{l}\text { Tidak mengkonsumsi } \\
\text { (Not to consume) }\end{array}$ & $\begin{array}{l}\text { MengKonsumsi } \\
\text { (To consume) }\end{array}$ & \\
\hline $\begin{array}{l}\text { Keputusan } \\
\text { mengkonsumsi } \\
\text { (Decision to } \\
\text { consume) }\end{array}$ & $\begin{array}{l}\text { Tidak mengkonsumsi } \\
\text { (Not to consume) }\end{array}$ & 17 & 14 & 54,8 \\
\hline & $\begin{array}{l}\text { Mengkonsumsi } \\
\text { ( To consume) }\end{array}$ & 6 & 83 & 93,3 \\
\hline $\begin{array}{l}\text { Persentase sec } \\
\text { (Total percentag }\end{array}$ & keseluruhan & & & 83,3 \\
\hline
\end{tabular}

Sumber (Source): Analisis data primer, 2009 (Primary data analysed, 2009)

\section{KESIMPULAN DAN SARAN}

\section{A. Kesimpulan}

Tingkat preferensi masyarakat Kabupaten Luwu dan Kabupaten Luwu Utara dalam mengkonsumsi sagu sangat terkait dengan faktor rasa, ketersediaan bahan baku, dan kebiasaan (adat istiadat). Sementara keputusan konsumen dalam mengkonsumsi makanan berbahan baku sagu dipengaruhi oleh faktor suku, pendidikan, jenis makanan olahan, dan harga beras. Dengan demikian, sagu berpotensi sebagai bahan makanan pengganti beras mengingat masyarakat semakin

Preferensi Masyarakat Terhadap Makanan Berbahan Baku Sagu (Metroxylon sagu Rottb) Sebagai Alternatif Sumber ..... (Nur Hayati et. al.) 
menyadari kandungan karbohidrat yang terdapat dalam sagu. Faktor lainnya adalah adanya berbagai jenis produk olahan sagu yang mampu menggugah selera sehingga produk olahan sagu tidak hanya digemari Suku Luwu tetapi dapat pula digemari oleh suku-suku lainnya yang ada di Sulawesi.

\section{B. Saran}

Untuk lebih memasyarakatkan penggunaan sagu sebagai bahan pagan alternatif pengganti beras maka pihak pemerintah daerah melalui Dinas Perdagangan, Perindustrian, Usaha Kecil dan Menengah (UKM) di Kabupaten Luwu dan Dinas Koperasi, Perindustrian dan Perdagangan di Kabupaten Luwu Utara perlu melakukan upaya diversifikasi produk olahan makanan berbahan baku sagu baik dari segi rasa maupun dari segi tampilan. Dengan upaya diversifikasi tersebut diharapkan produk makanan berbahan baku sagu tidak hanya digemari oleh Suku Luwu tetapi dapat pula digemari oleh suku lainnya di Sulawesi Selatan.

Usaha lainnya yang harus dilakukan oleh pemerintah daerah adalah dengan melakukan sosialisasi atau pemberian pemahaman kepada masyarakat bahwa sagu memiliki kandungan energi yang relatif setara dengan kandungan energi yang terdapat dalam beras yang dibutuhkan oleh tubuh dalam melakukan berbagai aktivitas. Hal ini dilakukan untuk mengurangi tingkat ketergantungan masyarakat terhadap beras jika sewaktuwaktu terjadi kegagalan panen. Disamping itu perlu adanya koordinasi antar stakeholder yang terkait dengan ketersediaan sumber bahan baku sagu dan industri pengolahan sagu. Pihak Dinas Kehutanan dan Perkebunan selaku intansi yang terkait dengan ketersediaan sumber bahan baku sagu perlu menggalakkan kembali kegiatan penanaman sagu di areal yang tersisa akibat alih fungsi lahan di Kabupaten Luwu dan Kabupaten Luwu Utara.

\section{DAFTAR PUSTAKA}

Badan Koordinasi Penanaman Modal. (2010). Potensi Sagu di Sulawesi Selatan. Diunggah dari http://regionalinvestment.bkpm.go.id/ newsipid/id/ commodityarea. php? $\mathrm{i}=708 \& \mathrm{ia}=73$.

Bisnis Indonesia. (2010). Produktivitas Tanaman Sagu Dipacu. Diversifikasi Bahan Pangan

Non Beras Belum Memuaskan. Bisnis Indonesia. Edisi Jumat 15 Oktober2010. Diunggah dari http://mirror.unpad.ac.id/ koran/bisnis/2010-10-15/bisnis 2010-1015 146.pdf.

Budiono, A. (2009). Sagu Sebagai Bahan Bakar Alternatif Penghasil Etanol. Diunggah dari www.RADARMERAUKE.COM.

Ebookpangan. (2006). Sagu Sebagai Bahan $\mathrm{P}$ angan. D i ung g h d a r i http://tekpan.unimus.ac.id/wpcontent/uploads/2013/07/SAGUSEBAGAI-BAHAN-PANGAN.pdf.

Gujarati, D. N. (2003). Basic Econometrics fourth edition. New York: McGraw Hill.

Hosmer, D. W. \& Lemeshow, S. (1989). Applied logistic regression. New York: John Wiley \& Sons Ltd.

Kuncoro, M. (2007). Metode Riset Untuk Bisnis dan Ekonomi Bagaimana Meneliti dan Menulis Riset. Jakarta: Erlangga.

Nassar, J. L. (1988). Environtmental Aesthetics Theory, Research and Application. Cambridge: Cambridge University Press.

Palopo Pos. (2011). Gagas Sejuta Pohon Sagu. Diunggah dari http://www.palopopos. co.id.

Permata, D. L. J. (2000). Preferensi Masyarakat terhadap Landskap Visual Pemukiman. Skripsi pada Fakultas Pertanian. Bogor: Institute Pertanian Bogor (IPB).

Pusat Penelitian dan Pengembangan Perkebunan. (2013). Seminar Triwulan Ke-4: Arti Penting Budidaya dan Pemanfaatan Sagu untuk Ketahanan Pangan dan Energi Nasional. Diunggah dari http://perkebunan. Litbang.deptan.go.id. 